Neues aus

Wissenschaft und Lehre Heinrich-Heine-Universität Düsseldorf

2010 



\title{
Neues aus \\ Wissenschaft und Lehre
}

\section{Heinrich-Heine-Universität Düsseldorf 2010}

\author{
Herausgegeben vom Rektor \\ der Heinrich-Heine-Universität Düsseldorf \\ Univ.-Prof. Dr. Dr. H. Michael Piper
}

Konzeption und Redaktion:

Univ.-Prof. em. Dr. Hans Süssmuth

$\mathbf{d}|\mathbf{u}| \mathbf{p}$ 


\section{(cc) BY-NC-ND}

This work is licensed under the Creative Commons Attribution-NonCommercial-NoDerivs 4.0 License. For details go to http://creativecommons.org/licenses/by-nc-nd/4.0/.

(C) düsseldorf university press, Düsseldorf 2010

Einbandgestaltung: Monika Uttendorfer

Titelbild: Blick in den Konrad-Henkel-Hörsaal

Redaktionsassistenz: Sonja Seippel

Beratung: Friedrich-K. Unterweg

Satz: Friedhelm Sowa, $\mathrm{ET}_{\mathrm{E}} \mathrm{X}$

Herstellung: WAZ-Druck GmbH \& Co. KG, Duisburg

Gesetzt aus der Celeste

ISBN 978-3-940671-71-4

eISBN 978-3-11-072005-1 